Institution. Dr. Brown was elected Fellow of the Royal Society in 1956.

\section{Senior Principal Scientific Officers}

DR. H. F. BARnes is deputy head of the Entomo. logy Department at Rothamsted Experimental Station. $\mathrm{He}$ is a world authority on gall midges and he has published widely on these and other insect pests.

DR. K. L. Blaxter, head of the Nutrition Depart. ment of the Hannah Dairy Research Institute, has been particularly concerned with research on problems related to the energy exchange of large farm animals.

Dr. G. A. Levvy is head of the Enzymology Department of the Rowett Research Institute. $\mathrm{He}$ is working in the field of the biochemistry of the glycosidases of their inhibition by aldonolactones.
One similar promotion to senior principal scientific officer has been made by the Atomic Energy Authority. Dr. P. E. Cavanagh, who is head of the beta-ray spectrometer group at Harwell, doing mainly basic research but also responsible for some technical developments, including that of the recording of nuclear-pulse data on magnetic tape. Achievements in basic research include the original observation of the double Compton effect-a higher order process in quantum electrodynamics-and the first accurate measurements of electron polarization violating parity.

The Development Commission has similarly promoted Dr. H. BARnes to senior principal scientific officer. Dr. Barnes has been a research chemist on the staff of the Marine Station, Millport, since 1946, and is well known for his work on physical and chemical oceanography. In addition, he has developed underwater television apparatus and is an authority on the biology of barnacles.

\title{
OCCUPATIONAL PSYCHOLOGY
}

$\mathrm{A}^{\mathrm{N}}$ MONG the best-attended meetings in Section $J$ (Psychology) of the British Association this year were those held during the occupational psychology session on September 1. Four papers were given in the course of the morning on which the session was held. Anyone looking for continuity or what the papers had in common might have remarked that the first dealt with competitive entry into industry in youth - trade apprentice selectionwhile the last dealt with retirement--largely compulsory retirement-from industry because of age. From another point of view there was also a certain similarity between the first three papers. All were, in a sense, directly concerned with problems of inspection; the first, 'inspection' of suitability for trade-apprenticeships in shipbuilding; the second, routine inspection of industrial products; and the third, systems of fault-finding in electronic equipment.

In the first paper, by Mr. J. G. McComisky (University of Hull) and Dr. P. P. Daws (University of Edinburgh), the introduction and development of an apprentice selection scheme in a Glasgow shipyard were described. In 1956, when the firm approached the Applied Psychology Unit of the University of Edinburgh for assistance, only about half the boys put on the firm's pre-apprentice trade courses were reaching the necessary standards to become indentured. In round figures, to obtain its quota of about 80 trade apprentices each year, the firm was obliged to put about twice this number through its preapprentice courses. All boys entered on courses were regarded as being likely to succeed. Following a review of the position when the firm asked for assistance, the following programme was decided on : (1) That immediate steps be taken to check the effectiveness of the firm's own system of initial selection. This consisted of an arithmetic test and an interview by the firm's apprentice supervisor. The arithmetic test was checked and found to be faulty. It was discarded and a new arithmetic test introduced. (2) That a selection scheme involving psychological testing be run for an experimental period of one year, and if the results warranted it, that this should replace the firm's existing system of selection. (3) That the selection scheme be developed in a way which would enable the firm's apprentice supervisor to run it with the need for no more than occasional advice and guidance from a psychologist.

Before experimental selection began, all secondyear trade apprentices in the firm were given the battery of psychological tests which it was proposed to use during the experimental phase of the scheme, the object being to see what relation there was between scores on the various tests and foremen's assessments of the second-year apprentices. A meeting was also arranged with the instructors on the pre-apprentice courses, the object being to enlist the co-operation of these in the projected scheme right from the beginning, and also to obtain information on the kinds of difficulties met by both instructors and boys on the pre-apprentice courses.

With the information and insights obtained from these sources experimental selection began. This, in practice, entailed giving all the boys on the firm's courses the battery of tests decided on, interviewing each for about 15 minutes, and then predicting whether or not the particular boy was likely to pass the course. An attempt was also made to spot particularly bright boys, as the firm was anxious to put these in line as early as possible for technical advancement in the firm. The degree of success in predicting failures and bright boys in the experimental year was encouraging enough to justify the procedure being put into effect as the official apprentice selection scheme of the firm.

In the first year of actual selection wastage on the courses dropped considerably: on the shipbuilding side-one of the two main divisions of the firm's apprenticeship system-it dropped from 42 to 22 per cent with a reduction of 33 per cent in the number of boys entered on courses. On the marine engineering side, the smaller division of the firm's apprenticeship system, the results were not as good, but the failurerate in the first year of real selection dropped to 
41 from 55 per cent in the previous year with the prospect of being further reduced. Work on improving the scheme is continuing. Dr. Daws, who has been supervising it for the past two years, has just discovered, for example, from his analysis of the relationship between scores on the tests and ability on the pre-apprentice courses, that the combined score of the five most effective tests in the battery- a verbal and a non-verbal intelligence test, a test in spatial ability, one in mechanical comprehension and one in arithmetic-mathematics-forms a most effective predictor when used alone. The refinement and adoption of this predictor will considerably simplify the selection procedure as a whole.

Since the full introduction of the scheme eighteen months ago it has been run by the firm's apprentice supervisor with the advice of Dr. Daws where necessary. In terms of cost the scheme has turned out to be comparatively inexpensive in both time and materials.

In the second paper, Mr. R. M. McKenzie (University of Edinburgh) described some of the factors making for good or bad relations between inspectors in industry and the workmen concerned. Some of the factors described involved considerations which were mainly economic, as, for example, where a bonus is paid only for work which has passed the inspector; other factors derived from the organization of the particular factory and the nature of the product, for example, in 'in-process' inspection where the particular products are checked while they are still being made so that any error of man or machine can be put right before a lot of bad work has been done. A third group of factors originate in the more purely human aspects of inspection, the fact that inspection with the prospect of adverse criticism is going on at all, whether or not the inspector is an older person than the general run of those whose work he is inspecting, what length of service he has had with the particular firm, and so on.

A consideration often discussed in connexion with inspection in industry is the nature of the inspector's qualifications for the job. Since the production man must be able to accept criticism from his inspector without losing face, it is a great help if the inspector is at least as well qualified technically as the operator or the charge-hand. He may, however, not need this skill to do the actual inspection. As Mr. McKenzie pointed out, "Many a man can grade an egg who could never lay one, but the man who grades the eggs can tell which hens are no use".

Another aspect of inspection which Mr. McKenzie dealt with was the frequent accusation that inspectors are inconsistent. A number of experiments which he himself had carried out showed that there is more to this criticism than an attempt to save face. In an experiment, for example, in checking subassemblies, one inspector rejected five out of a batch of fifty in one day but nine in the next. Another inspector rejected thirteen of the same batch. Two inspection-supervisors, as judges, considered that, in fact, eight were defective. The results of $\mathrm{Mr}$. McKenzie's experiments indicate clearly that the consistency of inspectors should not just be taken for granted. Factors which work against consistency include the fact that very often standards have simply not been clearly laid down. Often, too, the training of inspectors could be improved. Sometimes physical conditions such as the placing of lights or even the boredom of repetitive inspection are factors in poor consistency. It might be asked : Why do not inspector-supervisors check the accuracy of their inspectors? The reason, in practice, is usually found to be that very often relations with production are strained, and, as a consequence, the inspectorsupervisor tends to side with his inspectors. The result is that he sees himself first as an inspector and only very secondarily as a supervisor over inspectors.

In his summing up, Mr. McKenzie stressed the importance when picking inspectors of paying particular attention to whether or not they are likely to be acceptable to those over whom they are exercising authority. This is quite crucial since inspection is not just of the product but of the man who has made it ; because of this a reasonable working relationship must be established between the two sides. The quite anomalous position of the inspector in regard to both authority and pay in industry at the present time makes this all the more imperative. The inspector, for example, is not the workman's supervisor ; very often he has only the same rank as the operator himself, and in many cases receives even less pay. This makes a naturally difficult job even more exacting and underlines the need for appreciation of the importance of such qualities as tact and forbearance in the inspector in industry.

In the third paper, Mr. H. C. A. Dale (University of Cambridge) described an experimental programme on method of approach in fault-finding on which he is engaged. Mr. Dale began by pointing out that the overall efficiency of electronic equipment usually depends on the rapidity with which faults can be located and repaired. In other words, a good deal of the maintenance on it is remedial. Actual repair work usually presents no problem, but fault location does, and good fault-finders are in short supply. Mr. Dale's own research on the subject was aimed at determining the best way of training technicians to do fault-finding in an economic way.

Before addressing himself to the specific aspects of the problem, Mr. Dale gave a short description of basic design in electronic equipment as follows : electronic equipment consists basically of units arranged in chains. A signal or message flows through these chains, each unit making a slight change in it, rather like the way in which small changes are made to the product in a mass-production factory. The faultfinder has to search first for the chain which is faulty, then for the faulty unit, and finally for the component within this unit which is causing the trouble.

The question Mr. Dale then asked was: Can we expect persons to know the best way of searching in a system of this kind, or do they have to be taught ? In actual location of faults in electronic equipment when done in the most efficient way, three steps are essential: (1) discover which ehain is faulty; (2) locate the faulty unit; (3) find, within this unit, the faulty component.

Put briefly, the golden rule is: general questions are asked first, specific ones later. Mr. Dale then described the results of one of his experiments the main object of which was to see how far this systematic kind of fault-finding is adopted in actual practice. First, he set up laboratory fault-finding problems which involved searching in the same way as in the case of actual electronic equipment. In the particular experiment described, no more than six moves were necessary to locate the fault. The task was given to twenty-four subjects. All were thoroughly familiar with the idea of signal flow. Of the twenty- 
four, one only used a good solution. Eight of the twenty-four took ten moves or more. The common errors made were to move along in short steps instead of dichotomizing, to check junctions instead of chains, and to go into a chain before first finding if it contained a fault.

After describing the results of this experiment, $\mathrm{Mr}$. Dale went on to tell how he checked his finding against the kind of errors made by electronic engineers searching for real faults in real equipment. The evidence shows that there is a marked tendency to make the same kinds of errors in actual practice. A study carried out by Bryan in the United States, for example, showed that of seventy of the U.S. Navy's best technicians engaged on the maintenance of wireless sets, only 17 per cent of them dichotomized.

Mr. Dale concluded his paper by saying that the results of his experiments to date and those of other relevant studies indicate clearly that we cannot expect electronic engineers to know the best way of searching for faults. They need to be taught, and, it seems, they need to be taught by instructors in technical college, not by experience.

In the last paper of the session Dr. N. R. Cowan, medical officer of health, Rutherglen, Scotland, reported the results of an inquiry into the life-histories and opinions of 443 retired men, aged 65 to 93 years, who attended a Scottish Consultative Health Centre for older people. Approximately 80 per cent of the group had been compulsorily retired. The main purpose of the report on the inquiry given in the paper was to focus attention on the traumatic effect of retirement on the health of older men.

The information for the investigation was obtained from the men on a doctor-patient basis during their visits to the Centre. An analysis of the data showed how far it could be said that the members of the group were leading a 'full' life at the time when the inquiry was made. Three criteria of 'full' were used: physical activities, mental activities, and personal relationships. Each member of the group was given a 'high', 'medium', or 'low' rating on these, and, in addition, a grading for social status based on the occupational classification list of the General Register Office. This ranges through five levels, from class I (professional) to class V (unskilled). The distribution of the group along the five levels inclined towards the lower end : there were 24 in class I (professional) and 83 in class $\mathrm{V}$ (unskilled).

The results of the inquiry showed that 'high' ratings on the three criteria of a 'full' life were in no case above $\mathbf{1 0}$ per cent for the complete group and that these were found among men in classes I and II. The proportion of 'low' ratings was quite pathetic. In the case of 'mental activities' it was 44 per cent of the group, with 'personal relationships' at 32 per cent. It was apparent that the unskilled workers in the group tended to lead equally unskilled lives.

In the course of the paper Dr. Gowan directed attention to how the harshness of the fact that our economic system does not provide employment for all who wish to work operates to such a deplorable extent against men in the age-group covered in the inquiry. As he pointed out, it is a common occurrence to see older men unsuccessfully seeking work, and also those who have passed through this stage without finding employment, unhappily resigning themselves to retirement. 'There are, in addition, the partial casualties of compuIsory retirement-those who are forced to change their jobs late in life because of age. Of the men in the present group, 79 per cent regarded compulsory retirement as detrimental to the health of older men. One can only agree with Dr. Cowan's suggestion that until society provides some sort of education and preparation for retirement it has a social obligation to provide and subsidize congenial work for those who wish to do it.

This concluded the occupational session. It was a new venture this year in the Psychology Section of the British Association meeting and proved to be a rewarding one.

J. G. MCComisky

\section{ANALYTICAL CHEMISTRY, PHARMACY AND MEDICINE}

$I^{N}$ $\mathrm{N}$ his chairman's address to the British Pharmaceutical Conference at Llandudno on September 15, Dr. G. E. Foster, chief analyst of Burroughs, Wellcome and Co., expressed a more than personal pleasure in the election of an analyst to the chair. Such an election, he said, was a recognition of the indispensable services which chemical analysis rendered to pharmaceutical science and industry. The names of Scheele, Baumé and Mohr illustrated how analysis and pharmacy had always, in fact, gone hand-in-hand up to the establishment of 'classical pharmaceutical analysis'- - a stage which could perhaps be considered as embodied in the British Pharmacopoia of 1932.

In taking as his title "Modern Analytical Chemistry in the Service of Pharmacy and Medicine", Dr. Foster directed attention to the great pharmaceutical value of 'post-classical' developments in analysis. Developments which made it possible to work on very small amounts of material were of particular value, partly because of the very expensive nature of many modern drugs, and also because of their very high potency, which implied that only small amounts would be present in many preparations. For a number of drugs (adrenaline, atropine, carbachol, vitamin $\mathrm{B}_{12}$, digoxin, ergometrine, stilboestrol and physostigmine being among the examples quoted) the human dose was only a fraction of a milligram.

Classifying these techniques into microchemical and microbiological, Dr. Foster defined microchemistry as "ordinary ehemistry carried out on a small scale", and often with the aid of special instruments. Among these, the microbalance had its place; but it should be remembered that colorimetric methods-whether for actual assay of such drugs as morphine, ergot alkaloids or tubocurarine, or for the estimation of impurities such as trace metals - were also essentially microchemical in nature. The use of the photoelectric spectrophotometer in comparing colours of solutions, reducing error to about $t 0.1$ per cent as compared with about $\pm 5 \cdot 0$ per cent in visual comparisons, was given as an illustration of the improved sensitivity which instruments could achieve.

Of microbiological assays, Dr. Foster said these had made their way into very wide and intensive use, calling as they did for little more than standard 